\title{
An investigation on the effect of the corporation governance structure and free cash flow on over- investment
}

\author{
Mehdi Taghavi $^{\mathrm{a}}$, Mohammad Khodaei Valahzaghard ${ }^{\mathrm{b} *}$ and Neda Amirjahadi ${ }^{\mathrm{c}}$
}

\begin{abstract}
${ }^{a}$ Prof., Department of Management, School of Management and Human Sciences, Tehran North Branch, Islamic Azad University (IAU), Tehran, Iran
${ }^{b}$ Assist. Prof. \& Faculty Member, Department of Accounting, School of Management and Human Sciences, Tehran North Branch, Islamic Azad University (IAU), Tehran, Iran

${ }^{c}$ M.Sc. Student, Department of Accounting, School of Management and Human Sciences, Tehran North Branch, Islamic Azad University (IAU), Tehran, Iran

\begin{tabular}{l}
\hline C H R O N I C L E \\
\hline Article history: \\
Received July 28, 2013 \\
Received in revised format \\
20 November 2013 \\
Accepted 8 January 2014 \\
Available online \\
January 92014 \\
\hline Keywords: \\
Over Investment \\
Free Cash Flow \\
Corporate Governance
\end{tabular}
A B S T R A C T

This study examines the impact of corporate governance structure and free cash flow on overinvestment on 121 firms listed in Tehran Stock Exchange over the period 2008-2011. To measure over-investment, free cash flow and corporate governance variables based on available information reported on financial statements are gathered and using cross section regression method, different hypotheses of the survey are examined. The results indicate that among corporate governance mechanisms investigated in survey, there is a significant relationship between percentage of non-executive directors and ownership concentration with overinvestment. However, there was no meaningful relationship among controlling shareholders and duality with over-investment. Furthermore, a significant relationship between free cash flow and over-investment has been found.
\end{abstract}

\section{Introduction}

One of the primary concerns on stock market evaluation is to find suitable method for evaluating firms and there are literally different studies on firm evaluation and growth (Devine, 1983; Beneda, 2003; Lian \& Cheng, 2007; Kildegaard, 2008). Richardson (2006) for instance, investigated the extent of firm level over-investment of free cash flow and reported that over-investment was concentrated in companies with the highest levels of free cash flow. Further investigation examined whether firms' governance structures were associated with over-investment of free cash flow or not. The evidence recommended that certain governance structures, such as the presence of activist shareholders, seemed to mitigate over-investment.

*Corresponding author. Tel: +98-912-3443139

E-mail addresses: m khodaei@iau-tnb.ac.ir (M. Khodaei Valahzaghard) 
Xuesong et al. (2007) performed an empirical investigation on over-investment behavior and its restriction systems in China's listed companies. The results show that there were over-investment behaviors in China's listed firms. In addition, cash dividends and liabilities were effective restriction systems on over-investment behavior. In general, corporate governance could restrict overinvestment behavior. However, independent directors had no impacts on over-investment behavior. Mcmahon (2003) performed an exploratory study of under and over-investment amongst manufacturing SMEs from Australia's business longitudinal survey. They found some issues concerning the forms of manufacturing SME in terms of two disengagement configurations emerged in recent empirical development taxonomies for SMEs. Tao (2007) investigated the issue of corporate governance and over-investment of listed companies in China. Annual general meetings (AGMs) play essential role on corporate governance in the United Kingdom. Apostolides (2010) provided an analysis of AGMs and recommended different ways of making the event more effective from a stakeholder viewpoint such as providing a well balanced and independent range of skills and backgrounds on the board, accompanied by fair remuneration and reward schemes for the directors.

\section{The proposed study}

This study examines the impact of corporate governance structure and free cash flow on overinvestment on 121 firms out of 389 listed firms in Tehran Stock Exchange over the period 20082011. To measure over-investment, free cash flow and corporate governance variables based on available information reported on financial statements are gathered and using cross section regression method, different hypotheses of the survey are examined.

\subsection{Free cash flow}

Free cash flow in this study is calculated as follows,

Free cash flow $=$ operating cash flow - capital expenditure - dividend

\subsection{Over-investment}

In order to calculate over-investment, we first need to calculated new investments $\mathrm{I}_{\text {new,t }}$, which is calculated through the following regression model

$$
I_{\text {New }, t}^{*}=\propto+\beta_{1} Q_{t-1}+\beta_{2} \text { Leverage }_{t-1}+\beta_{3} \text { Cash }_{t-1}+\beta_{4} \text { Aget }_{t-1}+\beta_{5} \text { Size }_{t-1}+\beta_{6} \text { Stock Returns }_{t-1}+\beta_{7} \text { INew }_{t-1}+\varepsilon
$$

where $I_{\text {new,t }}$ is the investment appears in future, $Q$ is the growth opportunities, Tobin $Q$, which is calculated as follows,

$Q=\frac{\text { Market value }+ \text { Net debt values }}{\text { Net asset values }}$.

In addition, Leverage is the ratio of total liabilities to total assets, Cash represent total available cash, Age represents natural logarithm of the number of years the shares of the firm were traded on stock exchange, Size denotes the natural logarithm of total assets, Stock Return represents the return of firms, INew ${ }_{t-1}$ represents the previous year's new investments.

\subsection{Corporate Governance}

The proposed study of this paper uses the following regression model,

$O I_{i, t}=\beta_{1}+\beta_{2} F C F F_{i, t}+\beta_{3}$ BIND $_{i, t}+\beta_{4}$ BLOCK $_{i, t}+\beta_{5} \operatorname{CONTROL}_{i, t}+D U A L_{i, t}+\varepsilon$, 
where BLOCK is a dummy variable, which is equal to one if institutional investors hold more than $5 \%$ of total investment and 0 , otherwise. In addition, CONTROL is another dummy variable, which is equal to one if an investor holds over $50 \%$ of the investment and zero, otherwise. DUAL is the next dummy variable, which is one if managing director is acting as chief executive simultaneously and zero, otherwise. Finally, BIND is the ratio of the number of non-duty members of the board of directors on total number of directors.

The proposed study of this paper considers the following five hypotheses,

1. There is a meaningful relationship between BIND and over-investment.

2. There is a meaningful relationship between BLOCK and over-investment.

3. There is a meaningful relationship between CONTROL and over-investment.

4. There is a meaningful relationship between DUAL and over-investment.

5. There is a meaningful relationship between FFCF and over-investment.

Table 1 demonstrates the summary of some basic statistics.

\section{Table 1}

The summary of some basic statistics

\begin{tabular}{ccccccccc}
\hline Statistics & $R E T_{i, t-1}$ & $S I Z E_{i, t-1}$ & $A G E_{i, t-1}$ & $C A S H_{i, t-1}$ & $L E V_{i, t-1}$ & $Q_{i, t-1}$ & $I_{i, t-1}$ & $I_{i, t}$ \\
\hline Mean & 2.006083 & 13.28335 & 2.492617 & 0.032279 & 0.670322 & 4.745318 & 1.073610 & 0.678890 \\
Median & 0.380000 & 13.04376 & 2.484907 & 0.020219 & 0.656229 & 1.336609 & 0.035138 & 0.035367 \\
Std. Dev. & 12.49473 & 1.574960 & 0.637678 & 0.034493 & 0.341803 & 20.02128 & 11.00755 & 5.940940 \\
Skewness & 2.165369 & 0.800637 & -0.116805 & 2.781021 & 2.584761 & 17.62807 & 17.30307 & 17.75449 \\
Kurtosis & 22.88949 & 4.172159 & 2.842776 & 16.96638 & 16.70249 & 370.1665 & 329.5957 & 352.5077 \\
Jarque-Bera & 10445.00 & 99.27136 & 1.998837 & 5696.987 & 5406.739 & 3429701. & 2719029. & 3111124. \\
Sig. & 0.000000 & 0.000000 & 0.368093 & 0.000000 & 0.000000 & 0.000000 & 0.000000 & 0.000000 \\
N & 605 & 605 & 605 & 605 & 605 & 605 & 605 & 605 \\
\hline
\end{tabular}

In order to perform regression analysis, the study needs to find out whether the data are normally distributed or not. Fig. 1 demonstrates the residual of different variables, which indicate the normality of parameters.
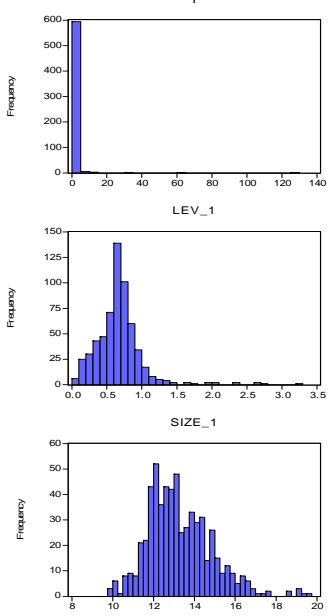

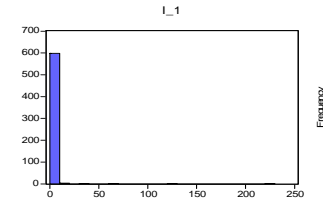

CASH ${ }_{-1}$

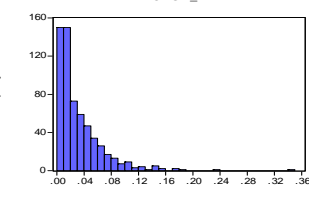

RET_1

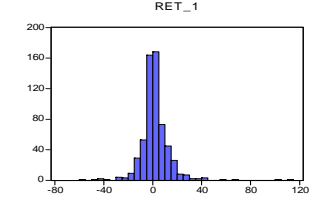

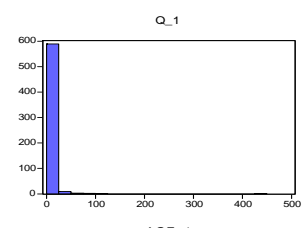

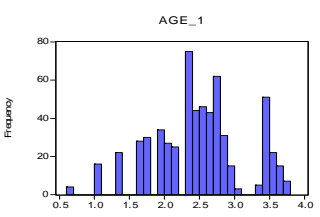

Fig. 1. The plot of residuals 
The study also needs to make sure that there was no strong correlation among any pairs of independent variables. Table 2 demonstrates the results of our survey.

Table 2

The results of correlation among different pairs of variables

\begin{tabular}{|c|c|c|c|c|c|c|c|c|}
\hline & Ii.t & Ii,t-1 & Qi,t-1 & LEVi,t-1 & CASHi,t-1 & AGEi,t-1 & SIZEi,t-1 & RETi,t-1 \\
\hline Ii.t & 1.000000 & & & & & & & \\
\hline Sig. & ----- & & & & & & & \\
\hline Ii,t-1 & 0.009154 & 1.000000 & & & & & & \\
\hline Sig. & 0.8222 & ----- & & & & & & \\
\hline Qi,t-1 & -0.004986 & 0.006664 & 1.000000 & & & & & \\
\hline Sig. & 0.9026 & 0.8701 & ----- & & & & & \\
\hline LEVi,t-1 & 0.055219 & -0.007111 & 0.093185 & 1.000000 & & & & \\
\hline Sig. & 0.1750 & 0.8614 & 0.0219 & ----- & & & & \\
\hline CASHi,t-1 & -0.025708 & 0.010460 & 0.014590 & -0.063225 & 1.000000 & & & \\
\hline Sig. & 0.5280 & 0.7974 & 0.7202 & 0.1203 & ----- & & & \\
\hline AGEi,t-1 & -0.007047 & 0.045928 & 0.022462 & -0.083416 & 0.042200 & 1.000000 & & \\
\hline Sig. & 0.8627 & 0.2594 & 0.5814 & 0.0403 & 0.3001 & ----- & & \\
\hline SIZEi,t-1 & -0.048391 & 0.003709 & -0.198407 & -0.134381 & -0.156756 & 0.179274 & 1.000000 & \\
\hline Sig. & 0.2346 & 0.9275 & 0.0000 & 0.0009 & 0.0001 & 0.0000 & ----- & \\
\hline RETi,t-1 & -0.021095 & -0.000536 & 0.040029 & -0.076030 & 0.045610 & -0.002125 & 0.027455 & 1.000000 \\
\hline Sig. & 0.6046 & 0.9895 & 0.3256 & 0.0616 & 0.2627 & 0.9584 & 0.5003 & ----- \\
\hline
\end{tabular}

The results of Table 2 show that there are not strong correlations between any pairs of data when the level of significance is five percent and we may perform the regression analysis.

\section{The results}

In this section, we present details of our survey on testing various hypotheses of the survey. First, we present the results of regression analysis on Eq. (1). Table 3 demonstrates the results of our survey.

Table 3

The results of regression analysis for the first model

\begin{tabular}{ccccc}
\hline Variable & $\beta$ & Standard error & t-student & P-value \\
\hline $\mathrm{C}$ & 0.2723 & 0.070387 & 3.8686 & -1.22 \\
$Q_{i, t-1}$ & $-4 \mathrm{E}-04$ & 0.000328 & 2.7344 & 0.0001 \\
$L E V_{i, t-1}$ & 0.1638 & 0.059892 & -3.408 & 0.0065 \\
$C A S H_{i, t-1}$ & -0.944 & 0.277017 & 1.7035 & 0.0007 \\
$A G E_{i, t-1}$ & 0.022 & 0.012886 & -3.545 & 0.0891 \\
$S I Z E_{i, t-1}$ & -0.017 & 0.004813 & -0.238 & 0.0004 \\
$R E T_{i, t-1}$ & $-3 \mathrm{E}-04$ & 0.001157 & 2.078 & 0.8117 \\
$I_{i, t-1}$ & 0.0052 & 0.002494 & 12.361 \\
$A R(1)$ & 0.0041 & 0.000328 & 0 \\
\hline F-value $=3.086$ Sig. $=0.002$ & Durbin-Watson $=2.079$ & Adjusted R-Square $=0.19$ Jarque-Bera $=753.33$ Sig. $=0.000$ F-Limer $=1.056$
\end{tabular}

Next, we present the results of regression model for the second model. Table 4 shows the results of some basic statistics.

\section{Table 4}

The results of some basic statistics on the second model

\begin{tabular}{ccccccc}
\hline Statistics & $D U A L_{i, t}$ & CONTROL $_{i, t}$ & $B L O C K_{i, t}$ & BIND $_{i, t}$ & $F_{C F F_{i, t}}$ & $O I_{i . t}$ \\
\hline Mean & 0.089974 & 0.334190 & 0.987147 & 0.614396 & 0.504420 & 0.479054 \\
Median & 0.000000 & 0.000000 & 1.000000 & 0.600000 & 0.009079 & 0.062257 \\
Std. Dev. & 0.286513 & 0.472314 & 0.112787 & 0.163715 & 5.564294 & 6.454798 \\
Skewness & 2.865860 & 0.703021 & -8.649452 & -0.111910 & 8.912527 & 19.25929 \\
Kurtosis & 9.213156 & 1.494238 & 75.81302 & 2.648828 & 119.1951 & 376.4506 \\
Jarque-Bera & 1158.181 & 68.79257 & 90782.68 & 2.810799 & 223983.4 & 2284549. \\
Sig. & 0.000000 & 0.000000 & 0.000000 & 0.245269 & 0.000000 & 0.000000 \\
N & 389 & 389 & 389 & 389 & 389 & 389 \\
\hline
\end{tabular}

Our survey indicates that there are not strong correlations among different pairs of variables. Therefore, we could present details of our findings on performing regression analysis on Eq. (2). Note 
that we have examined different types of regression techniques and Table 5 shows details of six different methods.

\section{Table 5}

The results of regression analysis for the second model of the survey

\begin{tabular}{|c|c|c|c|c|c|c|c|}
\hline & & $1^{\text {st }}$ model & $2^{\text {nd }}$ model & $3^{\text {rd }}$ model & 4rd model & $5^{\text {th }}$ model & $6^{\text {th }}$ model \\
\hline \multirow{2}{*}{$C$} & Coefficient & 0.268477 & 0.272410 & -0.060269 & 0.679954 & 0.521904 & 0.161066 \\
\hline & Sig. & $(0.1488)$ & $(0.0001)$ & $(0.0000)$ & $(0.2263)$ & $(0.2111)$ & $(0.3818)$ \\
\hline \multirow{2}{*}{$F C F F_{i, t}$} & Coefficient & 0.629090 & 0.839978 & 0.591928 & -0.005630 & -0.004905 & 0.478696 \\
\hline & Sig. & 0.0001 & $(0.0000)$ & $(0.0000)$ & $(0.3921)$ & $(0.4003)$ & $(0.3542)$ \\
\hline \multirow{2}{*}{$B I N D_{i, t}$} & Coefficient & & -0.476102 & & & & -0.381839 \\
\hline & Sig. & & $(0.0000)$ & & & & $(0.3837)$ \\
\hline \multirow{2}{*}{$F C F F_{i, t} \times B I N D_{i, t}$} & Coefficient & & -2.512934 & & & & -0.202325 \\
\hline & Sig. & & $(0.0000)$ & & & & $(0.2590)$ \\
\hline \multirow{2}{*}{$B L O C K_{i, t}$} & Coefficient & & & -0.784403 & & & 0.841285 \\
\hline & Sig. & & & $(0.0000)$ & & & $(0.1947)$ \\
\hline \multirow{2}{*}{$F C F F_{i, t} \times B L O C K_{i, t}$} & Coefficient & & & -0.247945 & & & -0.373660 \\
\hline & Sig. & & & $(0.0000)$ & & & $(0.3837)$ \\
\hline \multirow{2}{*}{$\mathrm{CONTROL}_{i, t}$} & Coefficient & & & & -0.573390 & & -0.646161 \\
\hline & Sig. & & & & $(0.2749)$ & & $(0.2246)$ \\
\hline \multirow{2}{*}{$\mathrm{FCFF}_{i, t} \times C O N T R O L_{i, t}$} & Coefficient & & & & 0.001314 & & -0.075890 \\
\hline & Sig. & & & & $(0.8860)$ & & 02703 \\
\hline \multirow{2}{*}{$D U A L_{i, t}$} & Coefficient & & & & & -0.380335 & -0.462823 \\
\hline & Sig. & & & & & $(0.2584)$ & $(0.2240)$ \\
\hline \multirow{2}{*}{$F C F F_{i, t} \times D U A L_{i, t}$} & Coefficient & & & & & -0.127452 & -0.171235 \\
\hline & Sig. & & & & & 0.4156 & $(0.7135)$ \\
\hline
\end{tabular}

For all models, all necessary statistics such as F-value, Durbin-Watson, Jarque-Bera are within acceptable limits and we can examine the hypotheses of the survey based on the results of different types of regression model presented in Table 5.

\section{The results}

In this section, we present details of our findings on testing various hypotheses of the survey.

\subsection{The first hypothesis: The relationship between BIND and over-investment}

The first hypothesis of this survey investigates the relationship between BIND and over-investment. Based on the results of Table 5 we have $\beta=-0.476102$, $\mathrm{p}$-value $=0.0000<p_{c}=0.05, \mathrm{t}=5.7252>\mathrm{t}_{\mathrm{c}}=1.96$.

Therefore, we can conclude that there was a meaningful and negative relationship between BIND and over-investment and the first hypothesis of this survey is confirmed.

\subsection{The second hypothesis: The relationship between BLOCK and over-investment}

The second hypothesis of this survey investigates the relationship between BLOCK and overinvestment. According to Table 5 we have $\beta=-0.784 \mathrm{P}$-value $=0.00<p_{c}=0.05 \mathrm{t}=4.298070>t_{c}=1.96$. Therefore, we can conclude that there was a meaningful and negative relationship between BLOCK and over-investment and the second hypothesis of this survey is confirmed.

\subsection{The third hypothesis: The relationship between CONTROL and over-investment}

The third hypothesis of this survey investigates the relationship between CONTROL and overinvestment. According to Table 5 we have $\beta=-0.57$, P-value $=0.2749>p_{c}=0.05, \mathrm{t}=-1.093415<t_{c}=1.96$. Therefore, we can conclude that there was not any meaningful relationship between CONTROL and over-investment and the third hypothesis of this survey is not confirmed.

\subsection{The fourth hypothesis: The relationship between DUAL and over-investment}


The fourth hypothesis of this survey investigates the relationship between DUAL and overinvestment. According to Table 5 we have $\beta=-0.38$ P-value $=0.2584>p_{c}=0.05 \mathrm{t}=0.336032<t_{c}=1.96$ Therefore, we can conclude that there was not any meaningful relationship between DUAL and overinvestment and the third hypothesis of this survey is not confirmed.

\subsection{The fifth hypothesis: The relationship between FFCF and over-investment}

The first hypothesis of this survey investigates the relationship between FFCF and over-investment. Based on the results of Table 5 we have $\beta=0.629 \mathrm{P}$-value $=0.0001<p_{c}=0.05 \mathrm{t}=3.979>t_{c}=1.96$. Therefore, we can conclude that there was a meaningful and negative relationship between FFCF and over-investment and the first hypothesis of this survey is confirmed.

\section{Conclusion}

We have examined the effect of corporate governance structure and free cash flow on overinvestment on selected firms listed in Tehran Stock Exchange over the period 2008-2011. The results have indicated that among corporate governance mechanisms investigated in survey, there was a significant relationship between percentage of non-executive directors and ownership concentration with over-investment. However, there was no meaningful relationship among controlling shareholders and duality with over-investment. Furthermore, a significant relationship between free cash flow and over-investment has been found.

\section{References}

Apostolides, N. (2010). Exercising corporate governance at the annual general meeting. Corporate Governance, 10(2), 140-149.

Beneda, N. L. (2003). Estimating free cash flows and valuing a growth company. Journal of Asset Management, 4(4), 247-257.

Devine, J. N. (1983). Underconsumption, over-investment and the origins of the Great Depression. Review of Radical Political Economics, 15(2), 1-27.

Kildegaard, A. (2008). Green certificate markets, the risk of over-investment, and the role of longterm contracts. Energy Policy, 36(9), 3413-3421.

Lian, Y. J., \& Cheng, J. (2007). Investment-cash flow sensitivity: Financial constraints or agency costs?. Journal of Finance and Economics, 2, 37-46.

Mcmahon, R. (2003). An exploratory study of under and over-investment amongst manufacturing SMEs from Australia's business longitudinal survey. International Small Business Journal, 21(1), 29-53.

Richardson, S. (2006). Over-investment of free cash flow. Review of accounting studies, 11(2-3), 159-189.

Tao, L. W. A. J. (2007). On corporate governance and over-investment of listed companies in China. Finance \& Trade Economics, 12, 012.

Xuesong, T., Xiaojing, S., \& Rujing, M. (2007). Empirical research on over-investment behavior and its restriction systems in China's listed companies. Accounting Research, 7, 44-54. 